\title{
Fabrication of polysilicon thin-film transistors using nickel/copper double-layer-induced lateral crystallization
}

\author{
Chi-Chieh Chen, Bo-Chuan Yang, and Si-Chen Lee ${ }^{\text {a) }}$ \\ Department of Electrical Engineering and Graduate Institute of Electronic Engineering, \\ National Taiwan University, Taipei, Taiwan, Republic of China
}

(Received 24 February 2004; accepted 24 January 2005; published 17 March 2005)

\begin{abstract}
The material properties and thin-film transistors characteristics of nickel/copper-induced polysilicon are investigated. It was discovered that by combining $\mathrm{Cu}$ and $\mathrm{Ni}$, the lateral growth rate of polysilicon is about an order of magnitude higher than that induced by $\mathrm{Ni}$ alone, and much better than the $\mathrm{Cu}$-induced case. The grain size of $\mathrm{Ni} / \mathrm{Cu}$-induced polysilicon is 1.5 times larger than that of $\mathrm{Ni}$ alone, and also 30 times larger than that of the $\mathrm{Cu}$ induced case. The mechanism is attributed to the $\mathrm{Cu}$-enhanced $\mathrm{Ni}$ silicide migration. The $\mathrm{Ni} / \mathrm{Cu}$-induced low-temperature polysilicon thin-film transistor shows a field-effect mobility of $10-25 \mathrm{~cm}^{2} / \mathrm{V} \mathrm{s}$, a threshold voltage of $8-22 \mathrm{~V}$, and an on/off current ratio about $10^{6}-10^{7}$. () 2005 American Vacuum Society. [DOI: 10.1116/1.1875312]
\end{abstract}

\section{INTRODUCTION}

Low-temperature polysilicon thin-film transistors (TFTs) have attracted wide attention in recent years because of their potential use in liquid-crystal displays (LCD) and organic light-emitting diodes. ${ }^{1-4}$ The most emphasized application of TFTs is the active-matrix liquid-crystal display, in which TFTs are used as the drivers of liquid-crystal cells. When the size of LCDs increases or higher resolution is required, the charging time for each pixel becomes shorter, which leads to the requirement that the on current of the TFT must be enlarged. It is believed that the electrical properties of TFTs can be improved if the grain size of the poly-Si can be enlarged. ${ }^{1}$ In the large-area processing of poly-Si TFTs, three techniques are applied: excimer-laser annealing, ${ }^{1-4}$ solid-phase deposition, and metal-induced lateral crystallization (MILC) of amorphous silicon (a-Si) ${ }^{5-11}$ MILC is proposed to crystallize a-Si by the catalytic effect of some metals. When certain metals are put in contact with the a-Si, the crystallization temperature of a-Si is dramatically reduced compared to that of conventional solid-phase crystallization. MILC using nickel $(\mathrm{Ni})^{5-11}$ gives a much larger poly-Si grain size $(>1 \mu \mathrm{m})$, but slower growth rate: $1-2 \mu \mathrm{m} / \mathrm{h}$. Other metals, such as palladium $(\mathrm{Pd})^{12}$ and copper $(\mathrm{Cu}),{ }^{13-15}$ can also induce poly-Si crystallization at a temperature of $550{ }^{\circ} \mathrm{C}$.

It was found that the mechanism responsible for copperinduced polysilicon is completely different from the case of Ni-induced polysilicon. This phenomenon has been attributed to two completely different nucleation mechanisms. ${ }^{14} \mathrm{In}$ the case of $\mathrm{Ni}^{5-11}$ it is due to the migration of $\mathrm{NiSi}_{2}$, which induced the a-Si to form poly-Si behind the $\mathrm{NiSi}_{2}$. In the case of $\mathrm{Cu},{ }^{14}$ the $\mathrm{Cu}$ silicide will form on top of $\mathrm{Cu}$ bars and release the latent heat of formation. This heat propagates out to the environment and helps to initiate the transformation of a-Si in neighboring area into poly-Si. This a-Si to poly-Si transformation further releases the latent heat to keep the

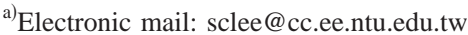

process continuing. Therefore, the phase transition from a-Si to poly-Si is induced by sufficient local heat or temperature. That is why a neighboring heat source (latent heat coming from neighboring $\mathrm{Cu}$ bars) is required to initiate the lateral growth of poly-Si. It is believed that the latent heat released from the formation of $\mathrm{Cu}$ silicide is larger than that of the $\mathrm{NiSi}_{2}$ and is close to the heat required to transform the a-Si to poly-Si at $550{ }^{\circ} \mathrm{C}$. Therefore, a neighboring heat source can supply the necessary heat and initiate the transformation process. In the Ni case, the neighboring heat source cannot provide enough heat to start the transformation, so that we do not see the same phenomenon. Because the heat conduction is much faster than the migration of $\mathrm{NiSi}_{2}$, that explains the faster lateral growth rate and thus smaller grain size of $\mathrm{Cu}-$ induced crystallization of poly-Si. ${ }^{14}$ This suggests to us that if both metals are used simultaneously (i.e., $\mathrm{Ni}$ and $\mathrm{Cu}$ ), we may gain both merits. Actually, three metal structures of $\mathrm{Ni}$ and $\mathrm{Cu}$ [i.e., nickel on copper $(\mathrm{Ni} / \mathrm{Cu})$, copper on nickel $(\mathrm{Cu} / \mathrm{Ni})$, and uniformly mixed $\mathrm{Ni}-\mathrm{Cu}$ alloy with weight ratio (40:60)] were studied. The results are presented in this article.

\section{EXPERIMENTS}

The fabrication process of $\mathrm{Ni} / \mathrm{Cu}$-induced polysilicon TFT is as follows. First, using an electron-gun (e-gun) evaporation system (FULINTEC FU-12CE), a Corning $1737 \mathrm{~F}$ glass substrate pre-annealed at $550{ }^{\circ} \mathrm{C}$ was patterned with photoresist and coated with 4-nm-thick copper (nickel), followed by 4 -nm-thick nickel (copper). Next, bars were formed by a lift-off process. In the case of $\mathrm{Ni}-\mathrm{Cu}$ alloy, $\mathrm{Ni}-\mathrm{Cu}$ alloy substituted for the $\mathrm{Ni}$ on $\mathrm{Cu}(\mathrm{Ni} / \mathrm{Cu})$ or $\mathrm{Cu}$ on $\mathrm{Ni}(\mathrm{Cu} / \mathrm{Ni})$ bars. After the metal deposition, the 50-nm-thick hydrogenated-amorphous silicon (a-Si:H) films were deposited on a Corning 1737F glass substrate by plasma-enhanced chemical-vapor deposition (PECVD) at $250{ }^{\circ} \mathrm{C}$. Next, using a high-temperature furnace in a $\mathrm{N}_{2}$ ambient, the samples were annealed to crystallize from a-Si:H to poly-Si. The crystallization conditions are as follows: loading the sample 


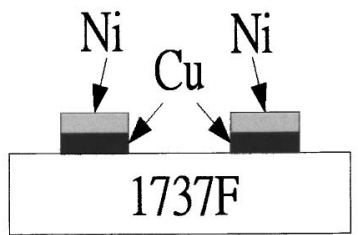

(a)

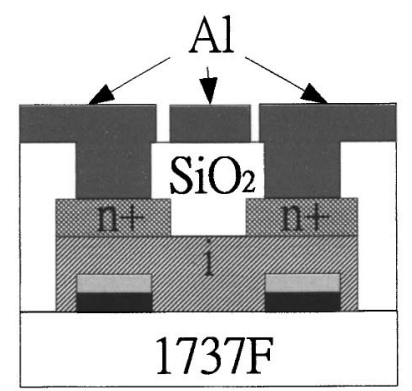

(b)

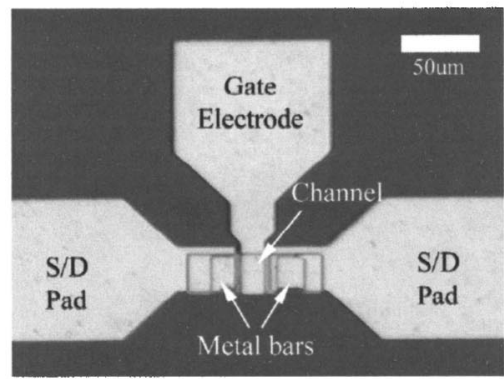

(c)

FIG. 1. Schematic diagrams showing the (a) substrate patterned by $\mathrm{Ni} / \mathrm{Cu}$ and (b) device structure of the TFT. (c) The top view of the device with width/length ratio of $30 \mu \mathrm{m} / 20 \mu \mathrm{m}$.

at $200{ }^{\circ} \mathrm{C}$, increasing the temperature to $550{ }^{\circ} \mathrm{C}$ at a rate of $4-5{ }^{\circ} \mathrm{C} / \mathrm{min}$, and keeping the sample at $550{ }^{\circ} \mathrm{C}$ for various times, then lowering the temperature to $200{ }^{\circ} \mathrm{C}$ at a cooling rate of $10{ }^{\circ} \mathrm{C} / \mathrm{min}$.

The fabrication processes of the nickel on copper (Ni/Cu)-induced polysilicon TFTs are as follows: first, 4-nm-thick copper, followed by 4-nm-thick nickel, was deposited by an e-gun evaporator on a pre-annealed $1737 \mathrm{~F}$ glass substrate over a photoresist mask using a lift-off process. Next 50-nm-thick undoped a-Si:H film and 20-nm $n^{+}$-type a-Si:H film were deposited on the prepared substrate by PECVD at $250{ }^{\circ} \mathrm{C}$. After PECVD, the $n^{+}$-type a-Si:H layer was patterned and etched by reactive-ion etching (RIE) to define the conducting-channel region of the TFT. The samples were then put into a high-temperature furnace at $550{ }^{\circ} \mathrm{C}$ for $8 \mathrm{~h}$ to fully crystallize the channel region. The temperature ramp rate was set to $2{ }^{\circ} \mathrm{C} / \mathrm{min}$. The sample was then mesa etched by RIE to define the device region and channel width. Next, using low-pressure chemical-vapor deposition, 150-nm low-temperature oxide was deposited at $550{ }^{\circ} \mathrm{C}$ as the gate insulator. The contact holes were defined by lithography and etched by RIE. Ammonia plasma was then used to passivate the poly-grain boundaries and $\mathrm{Si} / \mathrm{SiO}_{2}$

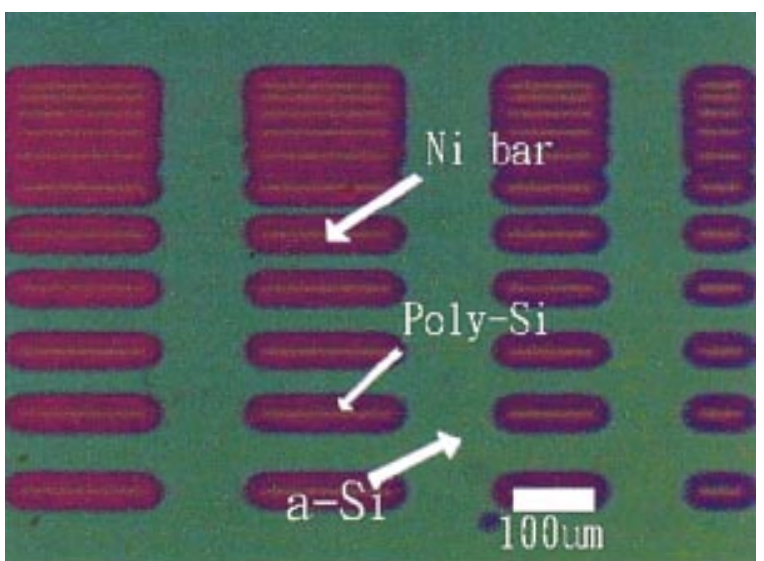

(a)

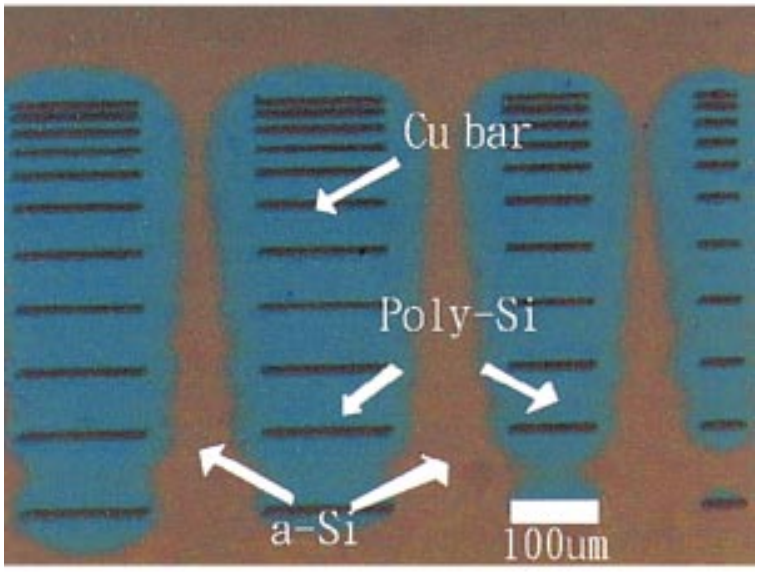

(b)

FIG. 2. Photographs showing the (a) nickel-induced, and (b) copper-induced polysilicon after annealing at $550{ }^{\circ} \mathrm{C}$ for $6 \mathrm{~h}$.

interface for $3.5 \mathrm{~h}$. Finally, 200-nm-thick Al-Si(1\%) was evaporated and patterned to form the source, drain, and gate electrode contacts of the TFT. The schematic view of the substrate patterned by $\mathrm{Ni} / \mathrm{Cu}$ and device structure of the TFT are depicted in Figs. 1(a) and 1(b), respectively. Figure 1(c) displays the top-view photograph under optical microscopy of a finished TFT.

\section{RESULTS AND DISCUSSION}

Figures 2(a) and 2(b) show the pictures taken by optical microscope of the typical nickel- and copper-enhanced lateral crystallization of poly-Si after annealing at $550{ }^{\circ} \mathrm{C}$ for $6 \mathrm{~h}$. Apparently, the growth rate of Ni-induced poly-Si is generally uniform and isotropic. As shown in Fig. 2(a), the shape of induced poly-Si follows the shape of $\mathrm{Ni}$ bars in all 


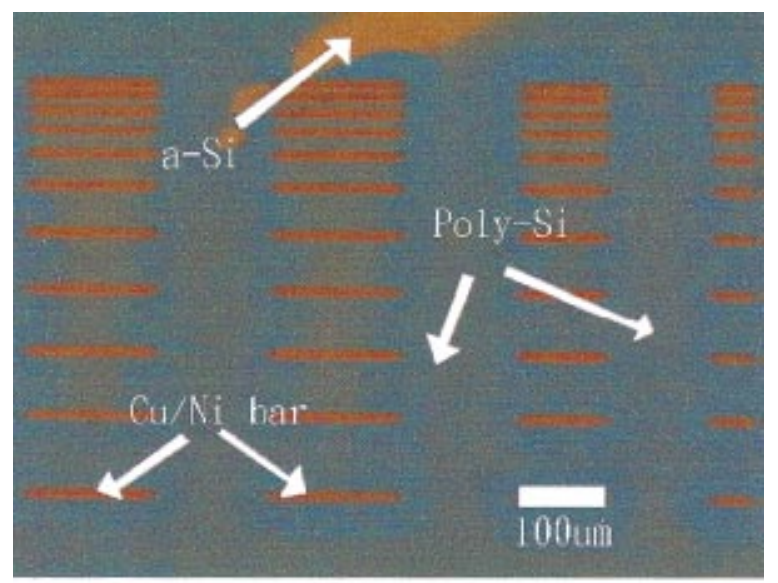

(a)

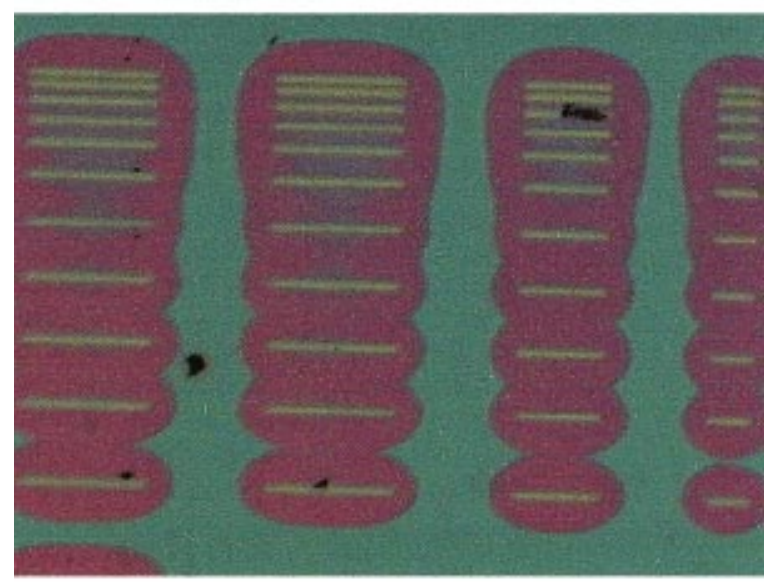

(b)

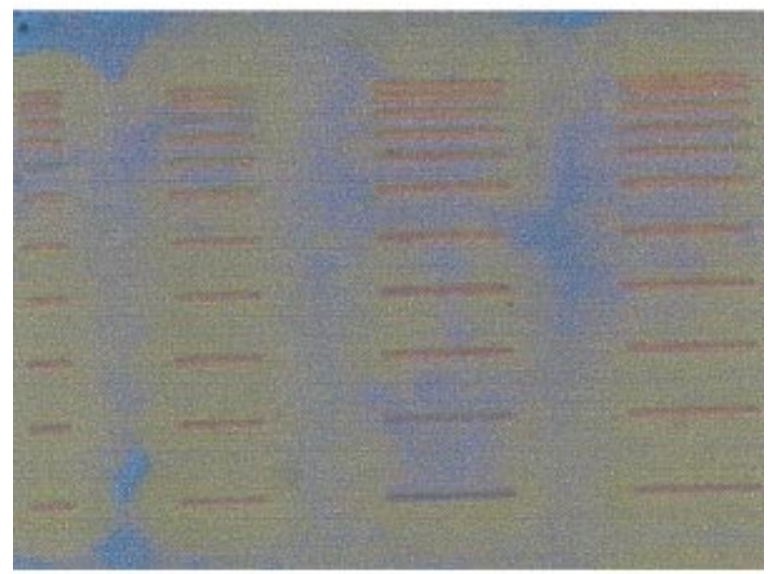

(c)

FIG. 3. Photographs showing the (a) $\mathrm{Ni} / \mathrm{Cu}$, (b) $\mathrm{Cu} / \mathrm{Ni}$, and (c) $\mathrm{NiCu}$ alloyinduced polysilicon after annealing at $550{ }^{\circ} \mathrm{C}$ for $6 \mathrm{~h}$.
TABLE I. Growth rate of $\mathrm{Ni} / \mathrm{Cu}, \mathrm{Cu} / \mathrm{Ni}$, and $\mathrm{Ni}$ alloy induced lateral crystallization of poly-Si.

\begin{tabular}{cccc}
\hline \hline & $\begin{array}{c}\text { Thickness } \\
(\mathrm{nm})\end{array}$ & $\begin{array}{c}\text { Growth rate } \\
(\mu \mathrm{m} / \mathrm{h})\end{array}$ & $\begin{array}{c}\text { Adherence to } \\
\text { glass substrate }\end{array}$ \\
\hline $\mathrm{Ni} / \mathrm{Cu}$ & $4 / 4$ & $\geqq 25$ & Excellent \\
$\mathrm{Cu} / \mathrm{Ni}$ & $4 / 4$ & $6 \sim 8$ & Good \\
$\mathrm{Ni} / \mathrm{Cu}$ alloy & 8 & $\geqq 25$ & Poor \\
$(40: 60)$ & & & \\
\hline \hline
\end{tabular}

directions. In the central region of Fig. 2(b) where many long $\mathrm{Cu}$ bars are closely spaced, $\mathrm{Cu}$ leads to a much faster growth rate. The growth rate is apparently nonuniform and the contour of the nucleation front is close to a circle, as can be seen from the lower-right corner of Fig. 2(b). Figures 3(a)-3(c) show the $\mathrm{Ni} / \mathrm{Cu}(\mathrm{Ni}$ on $\mathrm{Cu}), \mathrm{Cu} / \mathrm{Ni}(\mathrm{Cu}$ on $\mathrm{Ni})$, and $\mathrm{Ni}-\mathrm{Cu}$ (weight ratio 40:60) alloy-enhanced lateral crystallization of poly-Si after annealing at $550{ }^{\circ} \mathrm{C}$ for $6 \mathrm{~h}$, respectively. In the case of the $\mathrm{Ni} / \mathrm{Cu}(\mathrm{Ni}$ on $\mathrm{Cu})$ structure, obviously almost all of the amorphous silicon was transformed into poly-Si. The growth rate is hard to estimate, but it is higher than $25 \mu \mathrm{m} / \mathrm{h}$ (as listed in Table I), which is an order of magnitude higher than that of the Ni-induced case. In the case of $\mathrm{Cu} / \mathrm{Ni}(\mathrm{Cu}$ on $\mathrm{Ni}$ ), the growth rate is much slower than the $\mathrm{Ni} / \mathrm{Cu}$ case (i.e., $6 \sim 8 \mu \mathrm{m} / \mathrm{h}$ ), and the shape of poly-Si region is an ellipse more similar to the mixture of copper and nickel-induced case. This may be due to the lack of a contact region between $\mathrm{Ni}$ and $\mathrm{Si}$, so that copper dominates the crystallization process. However, Ni does play a role, as can be seen at the edge of the bar.

In the alloy case, the growth rate is as fast as in the $\mathrm{Ni} / \mathrm{Cu}$ case (i.e., $\sim 25 \mu \mathrm{m} / \mathrm{h}$ ), as listed in Table I. However, after the lift-off process, the alloy adheres poorly to the glass substrate. The lateral growth width a of $\mathrm{Ni} / \mathrm{Cu}$-induced lateral crystallization of poly-Si after annealing at $550{ }^{\circ} \mathrm{C}$ as a function of annealing time is shown in Fig. 4. The shape of poly-Si is more like the Ni-induced case, but with a much larger growth rate: $25 \mu \mathrm{m} / \mathrm{h}$. In Fig. 4, a large growth variation of $\mathrm{Ni} / \mathrm{Cu}$-induced poly-Si, especially when the anneal

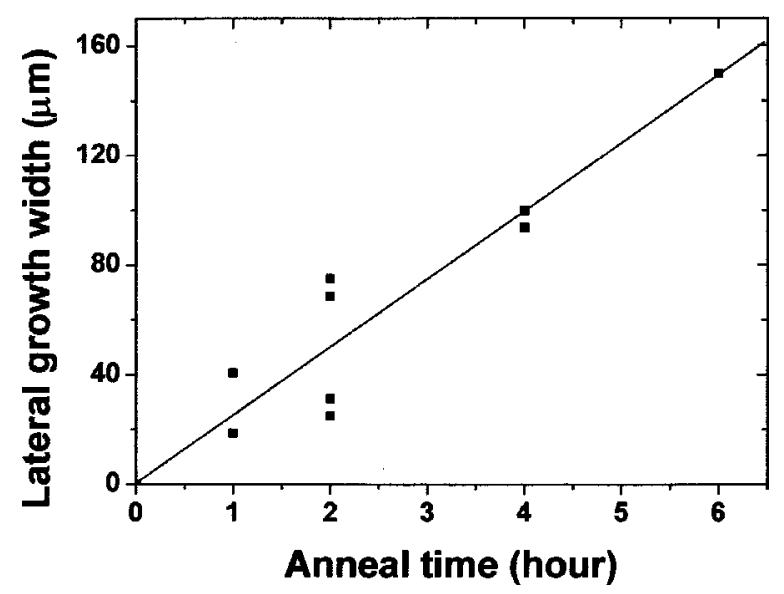

FIG. 4. Lateral growth width of poly-Si induced by $\mathrm{Ni} / \mathrm{Cu}(\mathrm{Ni}$ on $\mathrm{Cu})$ after $550{ }^{\circ} \mathrm{C}$ for different times. 


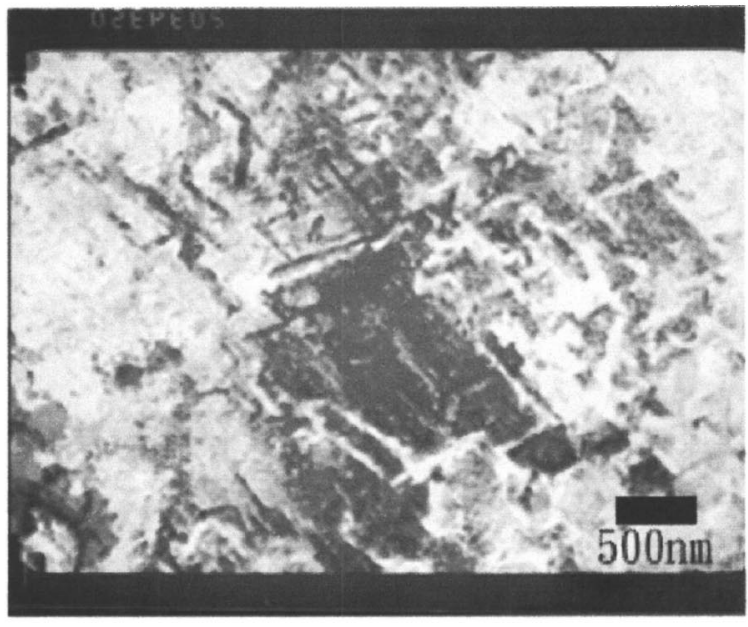

(a)

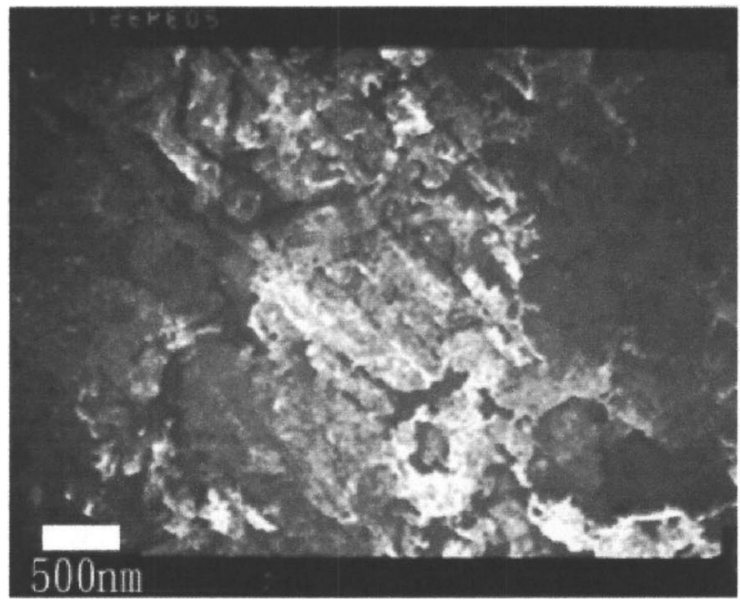

(b)

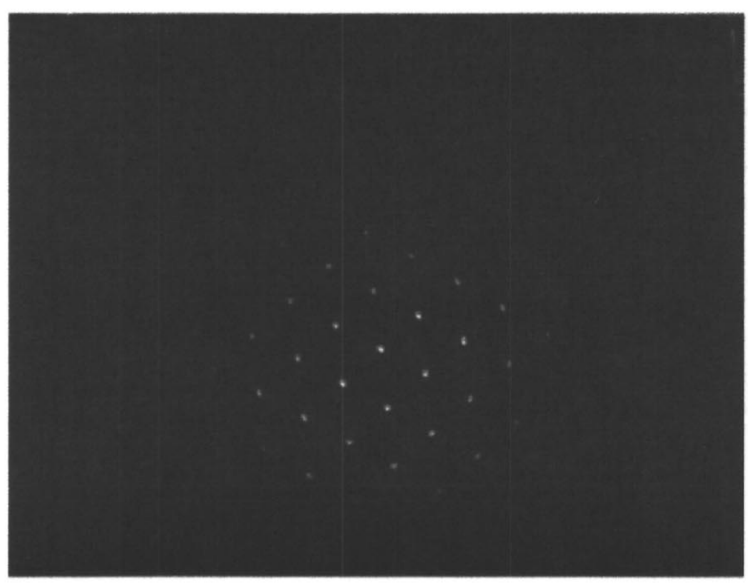

(c)
TABLE II. The heat conduction formula and the parameters used in the simulation. $\rho c(\partial u / \partial t)=f+\nabla(k \nabla u) ; \rho$ : density; $c$ : heat capacity; $k$ : thermal conductivity; $f$ : radiant heat source; $u$ : surface temperature; $n \cdot(k \nabla u)=q$ (with boundry condition); $n$ : direction vector; and $q$ : heat flux.

\begin{tabular}{lcc}
\hline \hline \multicolumn{1}{c}{ Materials } & $\mathrm{Si}$ & $\mathrm{Cu}$ \\
\hline$\rho:$ Density $\left(\mathrm{kg} / \mathrm{m}^{3}\right)$ & 2330 & 8700 \\
$c:$ Heat capacity $\left(\mathrm{J} / \mathrm{kg}^{\circ} \mathrm{C}\right)$ & 703 & 385 \\
$k:$ Thermal conductivity $\left(\mathrm{W} / \mathrm{m}^{\circ} \mathrm{C}\right)$ & 163 & 360 \\
\hline \hline
\end{tabular}

time was short ( 1 to $2 \mathrm{~h}$ ), occurred. This probably occurs for two reasons: first, the annealing time at $550{ }^{\circ} \mathrm{C}$ was harder to define at shorter annealing time because it took 1 to $2 \mathrm{~h}$ to raise the furnace temperature from 200 to $550{ }^{\circ} \mathrm{C}$. Second, the $\mathrm{Ni} / \mathrm{Cu}$ bars were exposed to the atmosphere after preparation; therefore, various oxides on the surface tended to result initially in nonuniform growth of poly-Si. The brightand dark-field images of transmission-electron microscopy

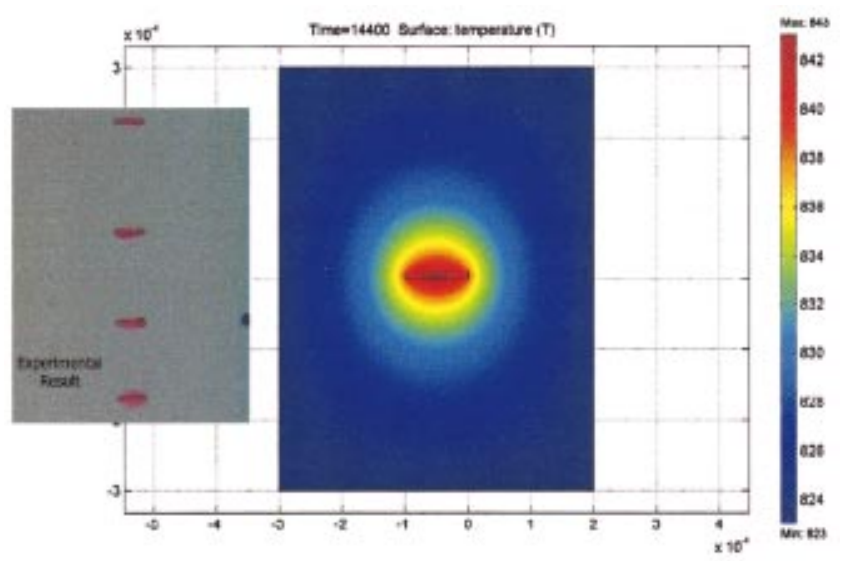

(a)

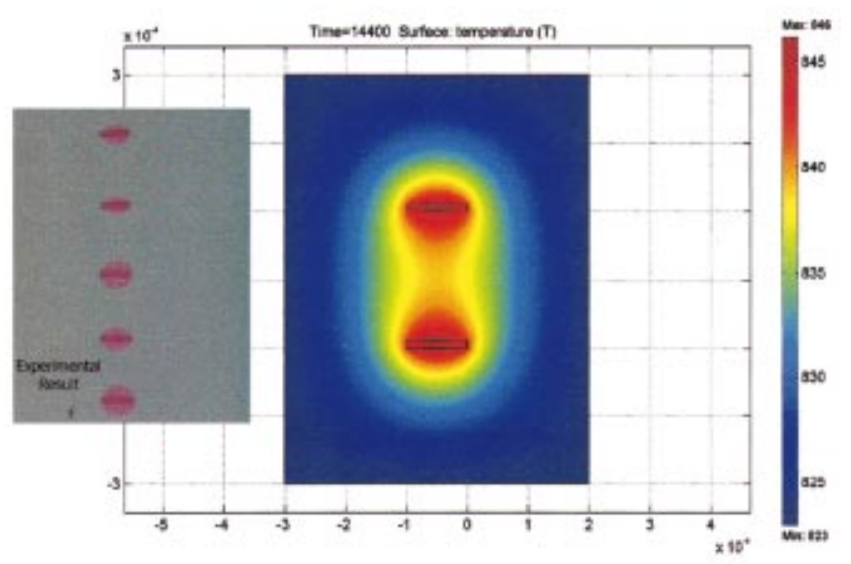

(b)

FIG. 6. Simulation of polysilicon induced by (a) one or (b) two copper bars.
FIG. 5. TEM images of $\mathrm{Ni}$ on $\mathrm{Cu}(\mathrm{Ni} / \mathrm{Cu})$-induced poly-Si. (a) Bright-field, (b) dark-field, and (c) diffraction patterns. 


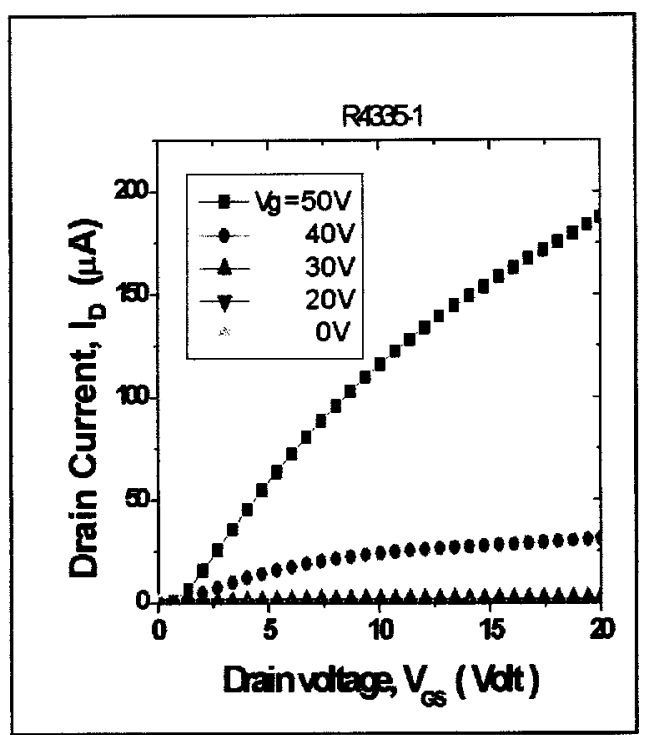

(a)

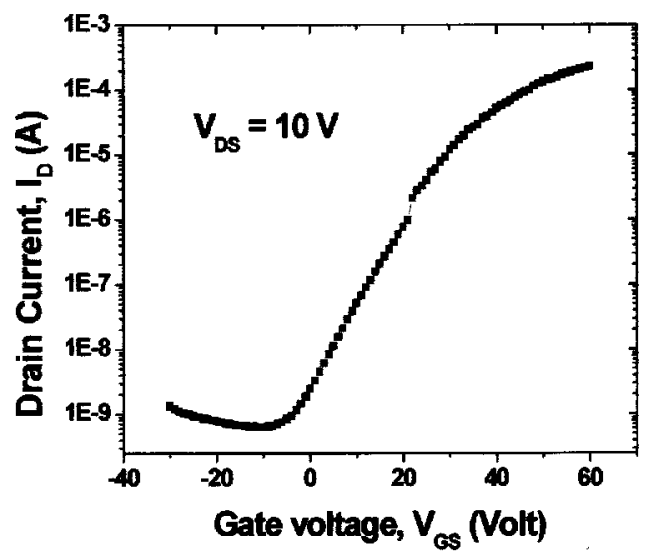

(b)

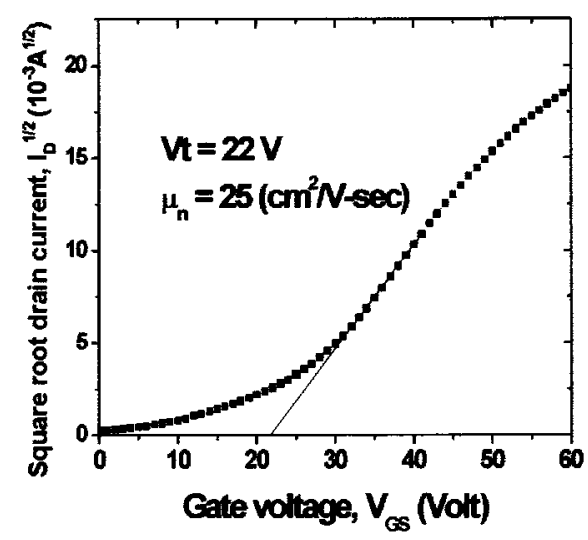

(c)

FIG. 7. Characteristics of (a) drain current $\left(I_{\mathrm{D}}\right)$ versus drain voltage $\left(V_{\mathrm{DS}}\right)$, (b) drain current $\left(I_{\mathrm{D}}\right)$ versus gate voltage $\left(V_{\mathrm{GS}}\right)$, (c) square root of $I_{\mathrm{D}}$, and gate bias $\left(V_{\mathrm{GS}}\right)$.

(TEM), and the transmission-electron diffraction of thermalenhanced Ni-induced polysilicon prepared by $\mathrm{Ni}$ on $\mathrm{Cu}$ $(\mathrm{Ni} / \mathrm{Cu})$ metal structure are shown in Figs. 5(a)-5(c), respec- tively. The average grain size is $1.5 \mu \mathrm{m}$, which is 1.5 times larger than that of nickel-induced polysilicon, and more than 30 times larger than that in the copper-induced case. ${ }^{14}$

According to the results of the above experiment, the heat-conduction model was used to simulate the shape of the poly-Si region under copper-induced lateral crystallization. It is assumed that the latent heat released from a-Si to poly-Si transformation is represented by the fixed heat sources at the perimeter of the $\mathrm{Cu}$ bar. The initial simulation results were obtained by using FEMLAB commercial software. Table II displays the heat-conduction formula and the material properties used in the simulation: the densities, heat capacities, and thermal conductivities of $\mathrm{Si}$ and $\mathrm{Cu}$. Figure 6(a) shows the simulation result of temperature distribution of poly-Si at the time of $4 \mathrm{~h}$ induced by a single copper bar and experimental data. Since the heat of formation of copper silicide $\mathrm{CuSi}_{3}$ is not known, the radiant heat source $\mathrm{f}$ (Table II) was chosen to create a $20^{\circ} \mathrm{C}$ temperature difference between the metal bars and environment. The assumed critical temperature $(843 \mathrm{~K})$ that can provide enough heat to form poly-Si (the deep red part) does not encompass the copper bar. Figure 6(b) shows the case of two copper bars at the time of $4 \mathrm{~h}$, where the deep red region $(843 \mathrm{~K})$ can clearly be seen to encompass the body of the bars. Apparently, the simulation can fit the experimental results of $\mathrm{Cu}$-induced lateral crystallization of poly-Si.

The drain-current versus the drain-voltage characteristics of the device are shown in Fig. 7(a). The width/length ratio of the devices is $30 \mu \mathrm{m} / 20 \mu \mathrm{m}$. Figure 7(b) shows the transfer curves of the TFT with $V_{\mathrm{DS}}=10 \mathrm{~V}$. The $10^{6}-10^{7} \mathrm{on} / \mathrm{off}$ current ratio can be obtained from this figure. The relationship between the square root of $I_{\mathrm{D}}$ and $V_{\mathrm{DS}}$ of the TFT biased in the saturation region $\left(V_{\mathrm{GS}}=V_{\mathrm{DS}}\right)$ is shown in Fig. 7(c). The field-effect mobility of $25 \mathrm{~cm}^{2} / \mathrm{V} \mathrm{s}$ can be obtained by evaluating the slope of Fig. 7(c). The threshold voltage of $22 \mathrm{~V}$ is extracted from the intercept of the square root of the $I_{\mathrm{D}}$ line and the $V_{\mathrm{DS}}$ axis.

\section{CONCLUSIONS}

Evidence is provided that the $\mathrm{Ni} / \mathrm{Cu}$-induced lateral crystallization of poly-Si is uniform, as in the case of $\mathrm{Ni}$, and is fast as in the case of $\mathrm{Cu}$. The crystallization is attributed to $\mathrm{Cu}$-enhanced $\mathrm{Ni}$ silicide migration. This technology can apparently shorten the process time of lateral crystallization of poly-Si and is suitable for industrial applications. It is demonstrated as a practical method for fabricating polysilicon TFTs by $\mathrm{Ni} / \mathrm{Cu}$-induced crystallization.

${ }^{1}$ P. G. LeComber and W. E. Spear, in Semiconductor and Semimetals edited by J. Pankove (Academic, Boston, 1984), Vol. 21, part D.

${ }^{2}$ K. Sera, F. Okumura, H. Uchida, S. Kaneko, and K. Hotta, IEEE Trans. Electron Devices 36, 2868 (1989).

${ }^{3}$ T. Aoyama, Y. Koike, Y. Okajima, N. Konishi, T. Suzuki, and K. Miyata, IEEE Trans. Electron Devices 38, 2058 (1991).

${ }^{4}$ S. D. Brotherton, D. J. McCulloch, J. B. Clegg, and J. P. Gowers, IEEE Trans. Electron Devices 40, 407 (1993).

${ }^{5}$ C. Hayzelden and J. L. Batstone, J. Appl. Phys. 73, 8279 (1993).

${ }^{6}$ V. W. C. Chan and P. C. H. Chan, IEEE Trans. Electron Devices 48, 1394 (2002). 
${ }^{7}$ D. Murley, N. Young, M. Trainor, and D. McCulloch, IEEE Trans. Electron Devices 48, 1145 (2001).

${ }^{8}$ W. Mingxiang and W. Man, IEEE Trans. Electron Devices 48, 1655 (2001).

${ }^{9}$ W. Man, J. Zhonghe, G. A. Bhat, P. C. Wong, and K. H. Sing, IEEE Trans. Electron Devices 47, 1061 (2000).

${ }^{10}$ M. Zhiguo, W. Mingxiang, and W. Man, IEEE Trans. Electron Devices 47, 404 (2000).

${ }^{11}$ W. Mingxiang, M. Zhiguo, and W. Man, IEEE Trans. Electron Devices
47, 2061 (2000).

${ }^{12}$ S. S. Lau and W. F. van der Weg, in Thin Films-Interdiffusion and Reactions, edited by J. M. Poate, K. N. Tu, and J. W. Mayer (Wiley, New York, 1978).

${ }^{13}$ S. W. Russil, J. Li, and J. W. Mayer, J. Appl. Phys. 70, 5153 (1991).

${ }^{14}$ W. C. Hsueh and S. C. Lee, IEEE Trans. Electron Devices 50, 816 (2003).

${ }^{15}$ S. Y. Kwon, K. W. Park, J. B. Lee, and D. K. Choi, J. Vac. Sci. Technol. B 20, 1427 (2002). 